\title{
Teachers' Perspective on a Health Promotion Intervention in Low Socioeconomic Status Kindergartens
}

\author{
Michal Pantanowitz ${ }^{1}$, Alon Eliakim¹, Narmen Igbaria ${ }^{2}$, Dganit Geva ${ }^{2}$, Dan Nemet ${ }^{1}$ \\ ${ }^{1}$ Child Health and Sports Center, Department of Pediatrics, Meir Medical Center, Sackler School of Medicine, Tel-Aviv University, \\ Kfar-Saba, Israel \\ ${ }^{2}$ The Wingate College of Physical Education and Sports Sciences at the Wingate Institute, Netanya, Israel \\ Email:michalmirochnik@gmail.com
}

How to cite this paper: Pantanowitz, M., Eliakim, A., Igbaria, N., Geva, D., \& Nemet, D. (2016). Teachers' Perspective on a Health Promotion Intervention in Low Socioeconomic Status Kindergartens. Advances in Physical Education, 6, 336-343. http://dx.doi.org/10.4236/ape.2016.64034

Received: August 8, 2016

Accepted: October 29, 2016

Published: November 1, 2016

Copyright $\odot 2016$ by authors and Scientific Research Publishing Inc. This work is licensed under the Creative Commons Attribution International License (CC BY 4.0).

http://creativecommons.org/licenses/by/4.0/

\begin{abstract}
Obesity is the most common chronic pediatric disease in westernized, especially low socioeconomic societies. We previously demonstrated the beneficial effects of a kindergarten dietary-physical activity intervention applied by the kindergarten teachers, on nutrition and physical activity knowledge and preferences, fitness, and BMI (Body Mass Index) percentile, even one year after the end of intervention. The current article demonstrates the Kindergarten teachers' feedback and perspectives on the intervention, a feedback that is important when planning such programs. Quantitative and descriptive feedback questionnaires were distributed to all kindergarten teachers twice, upon completion of the intervention program and one year after. Training kindergarten teachers on the importance of health promotion should be an integral part of their training curriculum. We believe that in our efforts to prevent and treat childhood obesity, a kindergarten dietary-physical activity health promotion intervention applied by kindergarten teachers may play an important role.
\end{abstract}

\section{Keywords}

Obesity, Preschool, Exercise, Nutrition, Kindergarten Teacher, Health Promotion

\section{Introduction}

The increasing prevalence of childhood obesity is a major public health concern throughout the world as well as in Israel (Cunningham, Kramer, \& Narayan, 2014; Lissau et al., 2004; Ministry of Health, Israel, 2013). Minorities and Low socioeconomic status groups are known risks factors to develop obesity both in adults and children 
(Cunningham, Kramer, \& Narayan, 2014; Sharma et al., 2009; Nemet, Geva, \& Eliakim, 2011).

The natural history of childhood obesity is that without intervention, the majority of the obese children will become obese adults (Cunningham, Kramer, \& Narayan, 2014). The most effective treatment for obese children is a multi-disciplinary program that includes medical, physiological, psychological, social and cultural components, all of which are essential for success. However, the high cost of these programs and their complexity makes them inaccessible for low socioeconomic status children. Moreover, it is clear that prevention of childhood obesity and health promotion through education should begin in early childhood. Integrating health promotion interventions into school curriculum, will allow access to these programs to most children.

Previously, we demonstrated the beneficial effects of a kindergarten dietary-physical activity intervention applied by the kindergarten teachers, on nutrition and physical activity knowledge and preferences, fitness, and BMI (Body Mass Index) percentile (Nemet, Geva, \& Eliakim, 2011; Nemet et al., 2005; Nemet, Perez, Reges, \& Eliakim, 2007). Effects were maintained one year after the end of intervention (Nemet et al., 2013). Since kindergarten teachers played a key part in our program, we were interested to get their perspective on the intervention, its success and applicability for future interventions. Kindergarten teachers who participated in our intervention program were asked to answer feedback questioners at the end of the intervention and after one year. The questionnaires were both quantitative and descriptive, in an effort to collect data on the kindergarten teachers' feedback on the intervention program design, benefits and difficulties.

\section{Methods}

\subsection{Participants and Procedure}

The study population included 785 children, mean age $5.2 \pm 0.02$ years, from 30 different kindergarten classes (15 intervention classes and 15 control classes). The participants were all reported healthy and lived in areas of low socio-economic status in Israel. Parents of the participants signed an informed consent. The study was approved by the Meir Medical Center IRB. The intervention outcomes were evaluated at the end of the intervention and at one year follow-up and were compared to baseline measurements performed at the beginning of the intervention. During the follow-up year, no structured intervention was performed.

\subsection{Intervention Design}

The most important factors in our intervention design were its transferability and frugality. We wanted to ensure that it will be possible to apply this intervention program to a large population of children, especially from minority groups.

The intervention kindergartens were randomly selected and their stuff was invited for a two-day training seminar. During the training the teachers got acquainted with the intervention and its goals. They were trained on the nutritional and exercise aspects of the intervention aimed to be performed by the kindergarten teacher and assistant 
teacher. The contents were given using hands-on sessions, written material and lectures. Over the course of the intervention year, the kindergarten teachers were asked to participate in supplementary training meetings. The aims of the training days were to gat and give feedback to the teachers as well as to supply additional materials to the kindergarten stuff. A summary meeting was conducted at the end of the intervention.

During the intervention, the study coordinator, a registered dietitian and a professional youth coach escorted the kindergarten stuff on a weekly basis. Kindergarten stuff, parents and children from the control groups were informed that the measurements were part of a survey on physical activity and nutrition among preschool children. The control kindergartens' daily routine was not changed.

Two "Health Festival" days were performed for the children and parents in the intervention groups. The aim of this activity was to involve the parents in the program and to encourage them to play an active role in the process of changing their children lifestyle to be healthier. The content of this days include introduction of healthy nutrition, prevention of childhood obesity and beneficial effects of exercise in children.

\subsubsection{The Nutritional Intervention}

The goal of the nutritional intervention was to improve nutritional knowledge and it was based on the nutritional program "It Fits Me" ("Tafur Alay") of the Israeli Ministry of Education (www.tafuralay.co.il). The main discussed issues were healthy food choices, the importance of drinking water, fruits and vegetables, fast-food versus home cooking and food preparation and cooking methods. All themes were carried by the kindergarten teachers and were taught through games, short lectures/talks and story reading. In addition, topics, such as, what do popular Israeli foods contain? Fruits and vegetables, what is calcium and why it is important and how to deal with food excess during celebrations, vacations, restaurants etc. were also covered. All the nutritional contents were made appropriate to the cognitive and social development levels of kindergarten children.

In order to involve the parents in this intervention program, monthly flyers describing nutritional topics discussed with the children were delivered home by the children. Parents and children were asked to discuss the nutritional material with each other.

\subsubsection{Physical Activity Program}

During the school week the kindergarten teacher and/or her assistant delivered a daily session of physical activity as instructed in the seminars. The daily session was $45 \mathrm{mi}-$ nutes long (divided to three 15 minute sessions), six days/week. Once a week, the exercise was delivered by a professional youth coach. The kindergarten and study stuff encouraged the children to increase their leisure time physical activity, and to reduce sedentary activities (e.g. television viewing, video games). In order to encourage movement during the daily routine at the kindergarten, the teachers got a CD collection of children songs, written by a famous Israeli children song writer, related to the topic of nutrition and exercise.

The main findings following the intervention were that our kindergarten dieta- 
ry-physical activity intervention applied by the kindergarten teachers lead to improved nutrition and physical activity knowledge and preferences, improved fitness, and decreased the percent of overweight children. Evaluating the teacher's perspective on the program may help us to further improve our intervention and the adherence of the teachers to it.

\subsubsection{Feedback Questioners}

The data of the current study were gathered through quantitative and descriptive feedback questioners. The questioners were distributed to all kindergarten teachers twice, upon completion of the intervention program and one year after.

The quantitative questionnaire included 12 questions aimed to study several aspects of the intervention program: if it doable, if it suitable for kindergarten children, if teachers' training was satisfactory and if the kindergarten teachers continue to use this program on a regular basis. The 12 items were united to eight categories by their main subject. Questionnaire presented separate questions for the physical activity and nutritional parts of the intervention as well as for the logistic part. Kindergarten teachers were asked to rate their opinions using a 5-point Likert scale ranging from very good to very weak.

The descriptive feedback questionnaire contained 11 open ended questions asked on aspects as the training program for the stuff, difficulties/barriers to operate the program, program implementation and suggestions for improvement.

All fifteen intervention kindergarten teachers participating in our study completed the questionnaires, all were female, mean age was $43.14 \pm 8.18$ years, mean seniority years as kindergarten teacher was $19.21 \pm 9.64$, from both Jewish-Israeli and ArabIsraeli sectors.

\section{Results}

\subsection{The Quantitative Feedback}

The quantitative feedback results are presented at Table 1 (mean \pm SD).

Interestingly, most end of intervention results were maintained after a year. Overall,

Table 1. Results of kindergarten teachers' opinion on the intervention program $(n=15)$.

\begin{tabular}{ccc}
\hline & End of the intervention & One year after the intervention \\
\hline I continue to implement the program & $4.6 \pm 0.5$ & $4.7 \pm 0.5$ \\
The program is doable & $4.6 \pm 0.5$ & $4.0 \pm 0.8$ \\
Nutritional influence & $4.3 \pm 0.8$ & $4.4 \pm 0.8$ \\
Physical activity influence & $4.6 \pm 0.6$ & $4.2 \pm 0.6$ \\
Children enjoyment from the program & $4.5 \pm 0.5$ & $4.9 \pm 0.3$ \\
Overall impression from the program & $4.7 \pm 0.5$ & $4.8 \pm 0.3$ \\
Personal influence on the kindergarten teacher & $3.7 \pm 1.0$ & $3.8 \pm 1.1$ \\
The program curriculum & $4.9 \pm 0.3$ & $4.45 \pm 0.5$ \\
\hline
\end{tabular}


the quantitative feedback was very positive with all categories rated above 4 , except those asking on personal influence on the kindergarten teacher ("I changed my dietary and physical activity habits because of the program", etc.) rated relatively lower on this questionnaire (3.7 - 3.8).

\subsection{The Descriptive Feedback}

\subsubsection{Training for the Kindergarten Staff}

The training days at the beginning of the intervention were reported to be important, raised the awareness of the stuff to childhood obesity, and to its difficult diagnosis in young age. Following the training days, some kindergarten stuff noticed for the first time overweight children in their kindergarten. Several of them began to be physically active due to their new awareness to the importance of healthy lifestyle and their responsibility as role-models. The stuff reported that a very significant part of the training days was the part in which they were introduced to the importance of physical activity in the young age and where given basic tools to act as physical activity guides to the children. This part of the program was initially the part that they felt insecure about, especially in the Arab-Israeli sector.

\subsubsection{Physical Activity Intervention Program}

As mentioned, involving the stuff in the physical activity part of the program was the most challenging part. The kindergarten teachers mentioned that the training days as well as basic accessories given to promote physical activity were very helpful (Children's songs $\mathrm{CD}$ and the physical activity lesson guide).

The kindergarten teachers stated that the professional physical youth coaches involved in the program were instrumental to the intervention program. This was emphasized at the Arab-Israeli sector, in which the previous knowledge and training of the kindergarten teachers in the subjects of healthy lifestyle was missing. The kindergarten teacher's noted that the weekly physical activity sessions guided by a physical youth coach were important both for the children and for teachers. Teachers used the assistance of the coaches to verify that their program was appropriate. The physical youth coaches were involved and assisted the teachers in all the program aspects, including nutritional and healthy lifestyle issues. According to the kindergarten teachers' the target of 45 minutes of exercise was achieved, although our initial suggestion of dividing the exercise to three 15 minute sessions, per day exercise training (six days/week), was hard to employ. Some of the kindergarten teachers mentioned that the children were very enthusiastic and energetic after the exercise so they preferred to continue the activity for 45 minutes. This was also the teachers' preference because it better incorporate in the daily routine of the kindergarten. The kindergarten teachers reported that the use of relaxation as yoga exercise at the end of the physical activity session was a successful tactic in order to gather the children back to continue the regular learning activities of the day. Most of the kindergarten teachers felt that the children's fitness and physical ability improved, especially among children with motor difficulties. A small part of the kindergarten teachers stated that they felt that at the age of kindergar- 
ten, the preferred physical activity was dancing and movement with music and not sports activities.

\subsubsection{The Nutritional Intervention Program}

The nutritional intervention part was harder for implement, since unlike the physical exercise program, it didn't have specific enough defined targets. The kindergarten teachers pointed that in order to improve the children's enjoyment from the nutritional program a better usage of games and more visual materials were warranted.

In conclusion, the kindergarten teachers felt that the involvement of external professionals was a key to the intervention program success. Beyond their knowledge and guidance, they were very cooperative, and showed a lot of personal involvement and concern that motivated the kindergarten stuff to be more committed to the program.

\subsubsection{Effect on the Kindergarten Routine}

The kindergartens' teacher was responsible to teach the curriculum. All kindergartens made sure that the topic of "healthy lifestyle" will be presented and a special board that presented the program was created. The children were very cooperative, especially in the physical activity part: dancing and exercise. As a result of the intervention program the eating habits in the kindergartens changed: sweets and snacks were reduced, fruits and vegetables consumption grow, whole grain bread replaced the white one, birthday celebrations were made healthier and the awareness for heathy food was developed. The kindergarten teachers pointed out that among downtrodden families, from low socioeconomic status, it was harder to develop healthier eating habits and implement them, since healthier food products are much more expensive and are usually not a top priority of the family. As our intervention results show (Nemet et al., 2013), the feedback from Arab-Israeli kindergarten teachers noticed a remarkable improvement in the children knowledge and awareness for healthy life style during the intervention program.

\subsubsection{Parents' Involvement at the Intervention Program}

All the kindergarten teachers highlighted the importance of the cooperation with the parents. They suggested organizing a pre intervention meeting with a health professional in order to explain the intervention program aims. Most of the parents didn't express any objection or criticism on the intervention program but were not involved in it. The "Health festival days" with the parents were a success. A small part from the Jewish-Israeli kindergarten teachers pointed out that the intervention program had an effect on the family eating habits at home. This effect was present only during the intervention year and did not last one year after. The Arab-Israeli kindergarten teachers felt that there was a positive influence on the family eating habits at home, and recommended to escort the intervention process with parents' on a monthly basis.

\subsubsection{Barriers to Success and Suggestion for Improvement}

1) Objection to the new eating habits and menu among children, parents and kindergarten staff. 
2) In some kindergartens, food is provided by a catering company. The kindergarten stuff or the study team had no influence on the foods' menu and components. All food suppliers should be supervised by the intervention program.

3) Lack in sports facilities and equipment.

4) Since kindergarten have a large number of children (up to 40), there are inherent differences in both knowledge and physical ability. This led the teachers to start with a common baseline levels that were sometimes not interesting/too easy for some children.

5) A behavioral change at the children's homes should be encouraged. This could be done by increasing the parents' involvement in the intervention program: sharing information, joint activities with the children, healthy lifestyle workshops etc.

6) There should be a continuity of the intervention program from kindergarten to elementary school.

\subsubsection{One Year Follow up}

Most of the kindergarten teachers stated that one year after the intervention, they are maintaining the subject of health promotion, healthy nutrition and water drinking only. When possible, fruits and vegetables variety and consumption are increased. Half of the kindergartens added a weekly physical activity session guided by a professional coach and purchased additional sport equipment. Yet, the total amount of daily physical activity in the kindergarten decreased after the end of the intervention due to lack of resources and other priorities dictated by the ministry of education curriculum.

Teachers felt that a very important and successful program was taken away from them, due to budgetary constraints and altered priorities. Their efforts to continue the program by themselves were not supported by the Ministry of education and it was very difficult for them to continue without outside (research) support. All teachers thought that the program should become an essential part of the kindergarten curriculum.

\section{Discussion}

We previously demonstrated that the beneficial effects of a kindergarten dietary-physical activity intervention applied by the kindergarten teachers, on nutrition and physical activity knowledge and preferences, fitness, and BMI percentile were evident at the end of intervention and one year after. The feedbacks, impression, difficulties and recommendations of the kindergarten teachers who took part in the intervention program should clearly be considered when designing an intervention program in kindergartens. Overall, the kindergarten teachers were satisfied with the intervention program. At the beginning, they felt that they lacked knowledge in healthy nutrition and physical activity that will enable them to teach those subjects. With the progression of the intervention, they felt more confident and were able to execute the intervention program as planned. We believe that health promotion should be an integral part of the training curriculum for kindergarten teachers. Clearly, the differences that were found between the Jewish-Israeli and Arab-Israeli sectors regarding knowledge and preferences were 
also reflected in the teachers feedback. As low socioeconomic and minority communities lack the appropriate resources for health promotion, and are the population at risk for the development of obesity and its complications, those communities should get more training in a culturally appropriate manner to encourage healthy lifestyle promotion.

A kindergarten dietary-physical activity intervention applied by the kindergarten teachers should be a part from the national educational curriculum. As seen in our report, when such an intervention is optional, and is not accompanied by professional guidance, unfortunately it will probably not last. We believe that our health promotion intervention program, with minor adaptations, as suggested by the teachers, may play an important role in the efforts to promote health, prevent and treat childhood obesity.

\section{Acknowledgements}

This work was supported by a grant from the Rosalinde and Arthur Gilbert Foundation and the Time for Action Fund.

\section{References}

Cunningham, S. A., Kramer, M. R., \& Narayan, K. V. (2014). Incidence of Childhood Obesity in the United States. New England Journal of Medicine, 370, 403-411. http://dx.doi.org/10.1056/NEJMoa1309753

Lissau, I., Overpeck, M. D., Ruan, W. J., Due, P., Holstein, B. E., \& Hediger, M. L. (2004). Body Mass Index and Overweight in Adolescents in 13 European Countries, Israel, and the United States. Archives of Pediatrics \& Adolescent Medicine, 158, 27-33. http://dx.doi.org/10.1001/archpedi.158.1.27

Ministry of Health, Israel (2013) School Age Growth Data in Israel 2010-2012. Jerusalem, Director of Public Health Services.

Nemet, D., Barkan, S., Epstein, Y., Friedland, O., Kowen, G., \& Eliakim, A. (2005). Short-and Long-Term Beneficial Effects of a Combined Dietary-Behavioral-Physical Activity Intervention for the Treatment of Childhood Obesity. Pediatrics, 115, e443-e449. http://dx.doi.org/10.1542/peds.2004-2172

Nemet, D., Geva, D., \& Eliakim, A. (2011). Health Promotion Intervention in Low Socioeconomic Kindergarten Children. The Journal of Pediatrics, 158, 796-801. http://dx.doi.org/10.1016/j.jpeds.2010.10.040

Nemet, D., Geva, D., Pantanowitz, M., Igbaria, N., Meckel, Y., \& Eliakim, A. (2013). Long Term Effects of a Health Promotion Intervention in Low Socioeconomic Arab-Israeli Kindergartens. BMC Pediatrics, 13, 1. http://dx.doi.org/10.1186/1471-2431-13-45

Nemet, D., Perez, S., Reges, O., \& Eliakim, A. (2007). Physical Activity and Nutrition Knowledge and Preferences in Kindergarten Children. International Journal of Sports Medicine, 28, 887890. http://dx.doi.org/10.1055/s-2007-965001

Sharma, A. J., Grummer-Strawn, L. M., Dalenius, K., Galuska, D., Anandappa, M., Borland, E. et al. (2009). Obesity Prevalence Among Low-Income, Preschool-Aged Children-United States, 1998-2008. Morbidity and Mortality Weekly Report, 58, 769-773. 
Submit or recommend next manuscript to SCIRP and we will provide best service for you:

Accepting pre-submission inquiries through Email, Facebook, LinkedIn, Twitter, etc. A wide selection of journals (inclusive of 9 subjects, more than 200 journals)

Providing 24-hour high-quality service

User-friendly online submission system

Fair and swift peer-review system

Efficient typesetting and proofreading procedure

Display of the result of downloads and visits, as well as the number of cited articles

Maximum dissemination of your research work

Submit your manuscript at: http://papersubmission.scirp.org/

Or contact ape@scirp.org 